\title{
The Influence of Social Comparison on Job Performance
}

\author{
Liangtie Dai, Rui Xiao \\ Management School, Jinan University, Guangzhou, China \\ Email: xiaorui_2014@163.com
}

Received 28 June 2016; accepted 18 July 2016; published 21 July 2016

Copyright (C) 2016 by authors and Scientific Research Publishing Inc.

This work is licensed under the Creative Commons Attribution International License (CC BY). http://creativecommons.org/licenses/by/4.0/

c) (i) Open Access

\begin{abstract}
The habit of comparing oneself with others can influence people's behavior in workplace and daily lives. This study focused on the effect of employee's social comparison orientation on job performance, and investigated 255 employees from enterprises and institutions in Hebei, Guangdong and some other provinces. The subjects were required to fill a questionnaire including three scales. Data analysis results showed that: social comparison orientation positively correlated with job performance. After controlling the demographic variables, ability comparison orientation and opinion comparison orientation both had a positive effect on job performance, including task performance and contextual performance.
\end{abstract}

\section{Keywords}

Social Comparison, Job Performance, Employee

\section{Introduction}

When we were just children, our teachers or parents often told us to compare ourselves with classmates, especially the top students, in order to make us more clear about our ability. This phenomenon is more obvious in China. Many people still prefer to compare with others when we grow up. Comparison is playing an important role in many people's lives.

This kind of phenomenon is called social comparison. It is an important way to get information about the self and the external world. People make comparison with others to evaluate their opinions, abilities and emotions. As a result, they may know about their social rank and similarity-difference [1], thus improve performance to reduce the gap.

The ability of comparing the self with others is rather old in the history of evolution, and biologically powerful, which can be found in many species [2]. However, it was not until 1954 when Festinger first proposed the theory of social comparison into social psychology. He suggested that people had a drive to evaluate his opi- 
nions and abilities by comparing respectively with others [3]. Since then, the process of social comparison has been studied extensively.

Many researchers hold the opinion that there existed individual differences in the disposition to compare the self with others [4], just like Diener and Fujita's argument that, “... making any comparison at all, may often be a function of one's personality" [5]. The comparison extent and frequency may have individual differences. In 1999, Gibbons and Guunk introduced the term social comparison orientation (SCO) to represent such individual differences. Consistent with Festinger's discussions, the structure of social comparison orientation is made up of two factors: comparison orientation of ability and opinion. The first one reflects an interest in performance comparison whereas the latter one is based more on opinions [6].

People with high SCO tend to relate themselves with those around them, and they are interested in other's thoughts and behaviors who are in similar situation with them [7]. A lot of evidence shows that people with high SCO prefer to compare with others, spend more time comparing and get more emotional experience in the process [8]. It has been proved that SCO can affect a variety of outcomes such as one's subjective well-being, risk perceptions, etc. In workplace, it may be related to such issues as occupational burnout [9] and openness to leadership behavior [10].

One of the most popular outcomes in Organizational Behavior is job performance. It has been a hot topic all the time. Job performance means how well a person does a piece of work. High performance means high profit, which is the result that every organization pursues. Therefore, leaders or managers as well as researchers keep exploring all kinds of factors that affect job performance for many years in order to practically improve employees' performance.

The Chinese are always educated to make comparison with the outstanding. Nevertheless, is the disposition of social comparison among employees affecting job performance in real life? A good rule of thumb is that comparing more often especially with others who are doing well may promote people's pursuit of success, thus produce better performance. In return, performing better than the competitors can help to remain performance [11]. On the other hand, one may seek out for self-enhancement through comparing downward with someone who is doing poorly [12], in order to improve confidence.

The behavior of social comparison is driven by three motivations: self-evaluation, self-improvement and selfenhancement. When a variance exists between the self and others, there will also be tendencies to make his position closer to others [3]. Studies have shown that those comparing with better students more often tend to have better academic performance [13]. Besides, negative performance feedback may promote the motivation of employees' performance, and also reflect the phenomenon of negative bias [14], that is the tendency of individuals to pay more attention to negative experiences or information.

From the above, it can be inferred that people with high social comparison orientation may have heightened motivation, which drives them to compare more with others and promote the behavior of improving and perfecting the self when they find a gap between themselves and the excellent ones.

The hypothesis is proposed: the higher disposition people have in social comparison, the more they compare themselves with others. Then they will find more negative bias, which may lead to heightened motivation for working harder and higher performance. That is to say, social comparison orientation has a positive effect on job performance.

\section{Method}

\subsection{Sample}

Data were collected from employees working in enterprises or institutions in Hebei, Guangdong and other provinces in China. All the questionnaires were released at the scene or through web. There were 255 valid surveys out of 278 , with a valid rate of $91.7 \%$. $52.5 \%$ of the subjects were male and $47.5 \%$ female. 115 people were under 30 years old, and another 140 were aged between 31 and 50. Most subjects had a bachelor's degree, accounting for $74.1 \%$. Another $8.2 \%$ were masters, and the others had college degree or below. 37 employees had worked for less than 2 years, 154 people had a working age between 3 - 10 years, and the rest of the subjects had worked for more than 10 years.

\subsection{Measures}

Social Comparison Orientation. The 11-item scale for SCO was developed by Gibbons and Buunk in 1999, 
which had been tested in over 60 studies [6]. Items are about whether people compare their personal situation with others, look for orientation in life by consulting others, or totally refuse any kind of social comparison, such as "I always like to know what others in a similar situation would do", "I always pay a lot of attention to how I do things compared with how others do things". It includes two factors: ability comparison orientation and opinion comparison orientation. In the present sample, Cronbach's alpha $=0.89, \mathrm{M}=39.52$, $\mathrm{SD}=7.33$.

Job Performance. The Job Performance Questionnaire was developed by Motowidlo and Van Scotterin 1994 [15]. It is made up of two questionnaires: the Task Performance Questionnaire and the Contextual Performance Questionnaire. It is on a set of statements reflecting task performance and behaviors that support social context where organizational work is accomplished, such as "I will complete the work in accordance with the standard operating procedures", "I will give my support and help when my colleagues have problems". In the present sample, Cronbach's alpha $=0.91, \mathrm{M}=93.10, \mathrm{SD}=9.16$.

The items were measured on a 5-point scale, ranging from strongly disagree (1) to strongly agree (5). Besides, the reversed items were recoded.

\subsection{Procedure}

The paper-pencil-questionnaires were released in four companies or institutions, and all of them were recovered in the field. A small gift was available to the employees who handed in the questionnaire. Besides, web based questionnaires were distributed to employees. They would click on an address that would take them to a secure web-site to fill in a questionnaire. Furthermore, they could also send an electronic version of the questionnaire to us by e-mail.

\subsection{Statistical Analysis}

The data were analyzed by Statistic Package for Social Science (SPSS). Correlation analysis and regression analysis was used to study the relationship between social comparison orientation and job performance.

\section{Results}

\subsection{Correlation Analysis between Social Comparison Orientation and Job Performance}

First, the correlation of social comparison orientation and job performance is analyzed. The results showed that: ability comparison orientation positively correlated with task performance $(r=0.22, p<0.01)$ and contextual performance $(r=0.38, \mathrm{p}<0.01)$; opinion comparison orientation also positively correlated with task performance $(r=0.36, p<0.01)$ and contextual performance $(r=0.44, p<0.01)$. Specific results are shown in Table 1 .

\subsection{Regression Analysis of Social Comparison Orientation on Job Performance}

In order to investigate the impact of social comparison orientation on job performance, regression analysis was performed, two factors of social comparison orientation as predictors and two factors of job performance as dependent variables. As shown in Table 2, controlling demographic variables like gender, age education background and working years, it was found that ability comparison orientation predicted job performance, including task performance $(\beta=0.20, \mathrm{p}<0.01)$ and contextual performance $(\beta=0.26, \mathrm{p}<0.001)$. Moreover, opinion comparison orientation predicted task performance $(\beta=0.34, \mathrm{p}<0.001)$ and contextual performance $(\beta=0.41$, $\mathrm{p}<0.001$ ).

Table 1. The correlation between social comparison orientation and job performance.

\begin{tabular}{|c|c|c|c|c|c|c|}
\hline & M & SD & 1 & 2 & 3 & 4 \\
\hline 1. Ability Comparison Orientation & 24.36 & 5.19 & 1 & & & \\
\hline 2. Opinion Comparison Orientation & 15.16 & 2.77 & $0.67^{* *}$ & 1 & & \\
\hline 3. Task Performance & 33.25 & 3.65 & $0.22^{* *}$ & $0.36^{* *}$ & 1 & \\
\hline 4. Contextual Performance & 59.85 & 6.19 & $0.28^{* *}$ & $0.44^{* *}$ & $0.71^{* *}$ & 1 \\
\hline
\end{tabular}

${ }^{* *} \mathrm{p}<0.01$. 
Table 2. The regression analysis of social comparison orientation on job performance.

\begin{tabular}{|c|c|c|c|c|c|c|c|}
\hline & & \multicolumn{3}{|c|}{ Task Performance } & \multicolumn{3}{|c|}{ Contextual Performance } \\
\hline & & Model 1 & Model 2 & Model 3 & Model 4 & Model 5 & Model 6 \\
\hline \multirow{4}{*}{ Step 1} & Gender & 0.05 & 0.04 & 0.06 & -0.06 & -0.07 & -0.05 \\
\hline & Age & 0.02 & 0.05 & 0.06 & -0.07 & -0.04 & -0.03 \\
\hline & Education Background & $0.26^{* * *}$ & $0.23^{* * *}$ & $0.22^{* * *}$ & $0.23^{* * *}$ & $0.20^{* *}$ & $0.18^{* *}$ \\
\hline & Working Years & 0.19 & 0.18 & 0.15 & 0.14 & 0.14 & 0.10 \\
\hline \multirow{5}{*}{ Step 2} & $\begin{array}{l}\text { Ability Comparison } \\
\text { Orientation }\end{array}$ & & $0.20^{* *}$ & & & $0.26^{* * *}$ & \\
\hline & $\begin{array}{l}\text { Opinion Comparison } \\
\text { Orientation }\end{array}$ & & & $0.34^{* * * *}$ & & & $0.41^{* * *}$ \\
\hline & $R^{2}$ & 0.11 & 0.15 & 0.23 & 0.06 & 0.13 & 0.23 \\
\hline & $\Delta R^{2}$ & & 0.04 & 0.12 & & 0.07 & 0.10 \\
\hline & $F$ & $7.91^{* * *}$ & $8.98^{* * *}$ & $14.52^{* * *}$ & $4.31^{* *}$ & $7.57^{* * *}$ & $15.13^{* * *}$ \\
\hline
\end{tabular}

${ }^{* * *} \mathrm{p}<0.001 ; \stackrel{*}{*} \mathrm{p}<0.01 ; \stackrel{\mathrm{p}}{\mathrm{p}}<0.5$

\section{Discussion and Expectations}

This study indicates that social comparison orientation is positively correlated with job performance. Both ability and opinion comparison orientation can positively predict job performance, including task performance and contextual performance. That is to say, the stronger the disposition to compare ability and opinion with others is, the better one will perform. This finding is consistent with prior researches [14] [15]. From this study, we know leaders should encourage competition among employees and arouse the enthusiasm of comparison. It will heighten employees' motivation to evaluate, improve and enhance the self, as well as lead to high personal and organizational performance.

There are also some limitations in this research. We have studied the relationship between social comparison orientation and job performance, but we still cannot confirm the internal mechanism. Are there any other variables, like organizational justice, that might have a mediating effect? Or does there exist any other mechanism in the relationship? Further research could take attention to mediators and moderators in how SCO affected job performance, and put forward more theoretical model.

With more and more study in Organizational Behavior, researchers get to know a lot of factors affecting employees’ performance. As a common personality and phenomenon in social psychology, social comparison orientation can be another factor influencing job performance, which should be paid more attention to. Employees need get to know more about the behavior of comparison, thus they can deepen awareness of themselves and others, be able to reexamine their characteristics and define their role. Organizations also need to know more about social comparison to understand employee psychology and develop effective policies to ensure the mental health of employees.

However, in real life, employees often compare themselves with others improperly, triggering jealousy, depression and other emotional problems, which may result in unfair competition and other bad behaviors, thereby affect normal work and life. Taking proper measures to influence the social comparison tendencies, helping employees change their ideas, and promoting reasonable competition will make it possible to create high performance. But how to make it come true will need more exploration and practice.

\section{References}

[1] Furnharn, A. and Brewin, C.R. (1988) Social Comparison and Depression. Journal of Genetic Psychology, 149, 191198. http://dx.doi.org/10.1080/00221325.1988.10532152

[2] Gilbert, P., Price, J. and Allan, S. (1995) Social Comparison, Social Attractiveness and Evolution: How Might They Be Related? New Ideas in Psychology, 13, 149-165. http://dx.doi.org/10.1016/0732-118X(95)00002-X

[3] Festinger, L. (1954) A Theory of Social Comparison Processes. Human Relations, 7, 117-140. 
http://dx.doi.org/10.1177/001872675400700202

[4] Buunk, A. P. and Dijkstra, P. (2014) Social Comparison Orientation and Perspective Taking as Related to Responses to a Victim. Psychology, 5, 441-450. http://dx.doi.org/10.4236/psych.2014.55054

[5] Diener, E. and Fujita, F. (1997) Social Comparison and Subjective Well-Being. In: Buunk, B.P. and Gibbons, F.X., Eds., Health, Coping, and Well-Being: Perspectives from Social Comparison Theory, Erlbaum, Mahwah, 329-358.

[6] Gibbons, F.X. and Buunk, B.P. (1999) Individual Differences in Social Comparison: Development of a Scale of Social Comparison Orientation. Journal of Personality and Social Psychology, 76, 129-142. http://dx.doi.org/10.1037/0022-3514.76.1.129

[7] Yang, L. (2011) Social Comparison of Employees and Their Relationship with Job Stress. Master Thesis, Nanjing Normal University, Nanjing.

[8] Buunk, A.P. and Gibbons, F.X. (2006) Social Comparison Orientation: A New Perspective on Those Who Do and Those Who Don't Compare with Others. In: Guimond, S., Ed., Social Comparison and Social Psychology: Understanding Cognition, Intergroup, Relationship, and Culture, Cambridge University Press, New York, 15-32.

[9] McIntyre, K.P. and Eisenstadt, D. (2011) Social Comparison as a Self-regulatory Measuring Stick. Self and Identity, 10, 137-151. http://dx.doi.org/10.1080/15298861003676529

[10] Gächter, S. and Thönid, C. (2010) Social Comparison and Performance: Experimental Evidence on the Fair WageEffort Hypothesis. Journal of Economic Behavior \& Organization, 76, 531-543. http://dx.doi.org/10.1016/j.jebo.2010.08.008

[11] Bandura, A. (1986) The Explanatory and Predictive Scope of Self-Efficacy Theory. Journal of Social and Clinical Psychology, 4, 359-373. http://dx.doi.org/10.1521/jscp.1986.4.3.359

[12] Gibbons, F.X., Blanton, H., Gerrard, M., Buunk, A.B. and Eggleston, T. (2000) Does Social Comparison Make a Difference? Optimism as a Moderator of the Relation between Comparison Level and Academic Performance. Personality and Social Psychology Bulletin, 26, 637-648. http://dx.doi.org/10.1177/0146167200267011

[13] Blanton, H., Buunk, B.P, Ribbons F.X. and Kuyper H. (1999) When Better-Than-Others Compare Upward: Choice of Comparison and Comparative Evaluation as Independent Predictors of Academic Performance. Journal of Personality and Social Psychology, 76, 420-450. http://dx.doi.org/10.1037/0022-3514.76.3.420

[14] Gino, F. and Staats, B.R. (2011) Driven by Social Comparisons: How Feedback about Coworkers’ Effort Influences Individual Productivity. Harvard Business School NOM Unit Working Paper, 11-078. http://dx.doi.org/10.2139/ssrn.1755051

[15] Motowidlo, S.J. and Van Scotter, J.R. (1994) Evidence That Task Performance Should Be Distinguished from Contextual Performance. Journal of Applied Psychology, 79, 475. http://dx.doi.org/10.1037/0021-9010.79.4.475

\section{Submit or recommend next manuscript to SCIRP and we will provide best service for you:}

Accepting pre-submission inquiries through Email, Facebook, LinkedIn, Twitter, etc.

A wide selection of journals (inclusive of 9 subjects, more than 200 journals)

Providing 24-hour high-quality service

User-friendly online submission system

Fair and swift peer-review system

Efficient typesetting and proofreading procedure

Display of the result of downloads and visits, as well as the number of cited articles

Maximum dissemination of your research work

Submit your manuscript at: http://papersubmission.scirp.org/ 